This is the accepted version of the article:

Merkoçi, A.. Electroanalysis-Based Clinical Diagnostics.

Electroanalysis, (2014). 26. 6: 1110 - .

10.1002/elan.201410132.

Available at: https://dx.doi.org/10.1002/elan.201410132 


\section{Electroanalysis-Based Clinical Diagnostics}

Editorial

It is a great pleasure for me to present to the readers of Electroanalysis this Special Issue dedicated to "Electroanalysis-Based Clinical Diagnostics". The demand for the development of novel diagnostic tools with interest for clinical analysis is increasing. Electroanalysis along with other detection technologies is becoming an authoritative tool with interest for various industries but is generating a particular enthusiasm in applications related to clinical analysis. In addition, recent developments in nano/microtechnologies and advanced materials are offering unprecedented new opportunities for the development of cutting edge diagnostic tools based on electroanalysis. These cost-effective devices are showing advantages for use in both clinical laboratories as well as in point of care applications. Potentiometry with ion-selective electrodes, controlledpotential techniques and electrochemical impedance spectroscopies, combined with a variety of nano/micromaterials are some of the electroanalysisbased technologies being offered for protein, DNA and even cell analysis with interest for diagnostics. The possibilities for clinical applications are enormous and the efforts are driven now not only to the design of novel and better electrochemical sensing systems but also to bringing of the developed device to end-users so as to fill the gap between the basic science and the real-world applied devices with interest for the market. This special issue gathers the latest achievements in the design, fabrication and applications of electroanalysisbased devices in clinical field. Both research and review papers related to various electroanalysis-based devices, including ion-selective electrodes, biosensors, lab-on-achip devices and other electrical/electrochemical platforms with interest for the analysis of DNA, proteins, cells and other clinically important analytes are presented. I wish the readers to enjoy this issue with great contributions by leading scientists and groups from all over the world working in the field of electroanalysis applied in clinical diagnostics. Sincere thanks for these high-quality contributions. I would like to thank professors Joseph Wang and Jose Pingarron for the invitation to edit this special issue and also would like to acknowledge my collaborator Dr. Eden Morales who has been efficiently working as handling editor of this issue. Many Thanks and Best Wishes!

Arben Merkoçi, Guest Editor ICREA \& Catalan Institute of Nanoscience and Nanotechnology (ICN2) Bellaterra (Barcelona), Spain 